\title{
MODERN MODELING OF WATER HAMMER
}

\author{
Kamil Urbanowicz \\ West Pomeranian University of Technology, Poland
}

\begin{abstract}
Hydraulic equipment on board ships is common. It assists in the work of: steering gear, pitch propellers, watertight doors, cargo hatch covers, cargo and mooring winches, deck cranes, stern ramps etc. The damage caused by transient flows (which include among others water hammer) are often impossible to repair at sea. Hence, it is very important to estimate the correct pressure runs and associated side effects during their design. The presented study compares the results of research on the impact of a simplified way of modeling the hydraulic resistance and simplified effective weighting functions build of two and three-terms on the estimated results of the pressure changes. As it turns out, simple effective two-terms weighting functions are able to accurately model the analyzed transients. The implementation of the presented method will soon allow current automatic protection of hydraulic systems of the adverse effects associated with frequent elevated and reduced pressures.
\end{abstract}

Keywords: hydraulic system,cavitation,water hammer,wall shear stress,weighting function

\section{INTRODUCTION}

Incompetent accelerating, stopping and sudden changes in direction of fluid flow in hydraulic systems are responsible for periodic pressure spikes. These spikes are referred to in hydraulics as water hammer and are directly related to the conversion of kinetic energy of flowing fluid into pressure energy. Pressure amplitudes at the moment when the aforementioned phenomenon occurs far outweigh the average working values and can easily lead to a leak in piping components.

One should be aware that the occurrence of a severe water hammer in hydraulic systems installed on ships (hydraulic systems for steering gear, pitch propellers, watertight doors, cargo hatch covers, cargo and mooring winches, deck cranes, stern ramps etc.) is not acceptable [4,12]. It is almost always associated with the occurrence of minor or major damage. Repairing the damage at the sea, is often impossible due to the lack of spare parts and if done temporarily it can quickly prevent the further safe travel of the ship.
Quick closing valves are the main element of hydraulic systems responsible for the impact force. Their installation must be preceded by a number of design tests. Due to the complexity of unsteady fluid flow in pressure lines, resulting from the superposition of the effects associated with many accompanying phenomena: cavitation $[1,3,5,6,9,14,17]$, FSI fluid structure interaction $[5,7,10,25]$, frequency dependent resistance $[2,8,13,15,16,17,19,21-23,26]$ or viscoelastic properties of polymer pipes $[6,10,11,25]$; it is necessary to use the help of numerical methods in the design calculations. They make it possible to solve partial differential equations, which describe the type of flow analyzed. The simplest method is the so-called method of characteristics [24], the use of which in this area has been known for over half a century. It has gained global application only after the development of personal computers. The main drawback of this method is its opacity, resulting from the complexity of the issue of modelling unsteady hydraulic resistance. This paper attempts to use a simplified method of calculating time-varying hydraulic resistance. Wall shear stress was presented as the 
sum of the quasi-steady and time-varying (expressed in a simplified manner) expressions.

\section{NEED FOR RAPID SIMULATION OF WATER HAMMERS}

Unsteady flow of fluids in pipes under pressure is described mathematically using a pair of continuity (1) and motion (2) equations [24]:

$$
\begin{gathered}
\frac{\partial p}{\partial t}+\rho c^{2} \frac{\partial v}{\partial x}=0 \\
\frac{\partial p}{\partial x}+\rho \frac{\partial v}{\partial t}+\rho g \sin \gamma+\frac{2}{R} \tau_{w}=0
\end{gathered}
$$

where: $\mathrm{p}$ - pressure, $\mathrm{t}$ - time, $\rho$ - density, $\mathrm{c}$ - speed of pressure wave propagation, $\mathrm{v}$ - flow velocity, $\mathrm{x}$ - axis coordinate, $\mathrm{g}$ - acceleration due to gravity, $\gamma$ - pipe tilt, $\mathrm{R}$ - inner radius, $\tau_{\mathrm{w}}$ - wall shear stress.

The key parameter of hydraulic resistance in the equations written out above is wall shear stress $\tau_{\mathrm{w}}$ occurring in the motion equation. In this work, this stress is calculated from the sum of two expressions:

$$
\tau_{\mathrm{w}}=\tau_{\mathrm{q}}+\tau_{\mathrm{u}}
$$

The subscript "q" means that the expression is calculated using the quasi-steady method, while the expression with subscript " $\mathbf{u}$ " is directly related to the non-stationarity of flow. The accuracy of the simulated pressure runs depends on the method of expressing the unsteady expression $\tau_{\mathrm{u}}$ and the number of simplifications assumed in the numerical solution of the system in the aforementioned equations. The method of characteristics is a widely known and recognized method for solving these equations. The calculations applied in this method are carried out on all calculation nodes, distributed evenly along the length of the pipe. They represent subsequent cross-sections of the analyzed pressure line for discrete moments of time, evenly occurring from the appearance of non-stationarity, until the final analysis. The more nodes (in cross-sections along the length of the pipe) are included in the calculations, the more instantaneous values of the basic parameters (pressure and velocity) describing the flow will need to be determined. Numerical calculations therefore take much more time. Current advanced control systems, to effectively protect systems against possible adverse events occurring at the time of the emergence of non-stationary conditions, necessitate continuous development of numerical methods. In terms of control, the ideal situation would take place at a time when a simple computer controlling a hydraulic system would be able to predict basic flow parameters, in advance, through a simplified computer simulation. This will allow for finding an early correct answer regarding the appropriate controls for the given system. Systems will then be protected using follow-up control against too high and too low pressures. High pressure can cause damage due to leaks, low pressure is responsible for the occurrence of cavitation areas causing rapid erosion of the inner surface of the piping. Application of follow-up control methods discussed above eliminates the need to install currently known and used expensive damping devices (air water tanks or modern bleed valves) which role is to protect hydraulic systems against damaging effects associated with a pressure surge.

As noted above, increasing the speed of modelling pressure in the piping is a very important issue, which will enable further systematic development of control methods. During the modelling of unsteady hydraulic resistance, the use of simplified weighting functions, constructed from only two or three exponential expressions, in combination with a method lumping unsteady friction [8] only in the boundary nodes (the inlet and outlet of the pipe), will allow to considerably unburden the numerical mathematical process.

It remains to be checked if the results of simulated runs will have a sufficient accuracy with such a large number of simplifications? This paper will try to answer this question, especially in the next chapter, where results of the research carried out will be described.

\section{RESEARCH SCOPE AND RESULTS}

The weighting functions, composed of multiple exponential expressions, significantly increase operating time of a computer, as the number of expressions describing them is also the upper summation index necessary to determine the unsteady part of wall shear stress in each node of the characteristic grid. Refinement of effective numerical solution of the convolution integral:

$$
\tau_{\mathrm{u}}=\frac{2 \mu}{\mathrm{R}} \int_{0}^{\mathrm{t}} \mathrm{w}(\mathrm{t}-\mathrm{u}) \frac{\partial \mathrm{v}}{\partial \mathrm{t}}(\mathrm{u}) \mathrm{du}
$$

where: $\mu$-dynamic viscosity, $\mathrm{w}(\mathrm{t}-\mathrm{u})$ - weighting function, describing the unsteady expression of wall shear stress, presented in the paper by Urbanowicz and Zarzycki [18], made it possible to limit the scope of applicability representing the effective weight function used from the previously recommended range $\left[10^{-3} \Delta \hat{\mathrm{t}} ; \infty\right)$ to $[\Delta \hat{\mathrm{t}} ; \infty)$. Subsequent research has shown that this range may be further limited to $\left[\Delta \hat{\mathrm{t}} ; 10^{3} \Delta \hat{\mathrm{t}}\right]$ without noticeably decreasing the accuracy of the calculations [19]. Two and three expression functions used in the simulations carried out in this project will feature this narrow range. The number of expressions representing an effective weighting function is related to the numerical solution of the convolution integral used for calculating wall shear stress in the calculation nodes for the method of characteristics in the following way [18]: 


$$
\begin{aligned}
\tau_{w(t+\Delta t)} & =\frac{\rho \lambda_{(t+\Delta t)} v_{(t+\Delta t)}\left|v_{(t+\Delta t)}\right|}{8}+ \\
\frac{2 \cdot \mu}{R} \cdot \sum_{i=1}^{j} & \underbrace{\left[\begin{array}{l}
y_{i(t+\Delta t)} \cdot A_{i}+\eta \cdot B_{i} \cdot\left[v_{(t+\Delta t)}-v_{(t)}\right] \\
{[1-\eta] \cdot C_{i} \cdot\left[v_{(t)}-v_{(t-\Delta t)}\right]}
\end{array}\right]+}_{y_{i}(t+\Delta t)}
\end{aligned}
$$

where: $\lambda$ - hydraulic resistance coefficient, $\eta$ - weighting function correction factor, $\Delta \mathrm{t}$ - numerical time step.

Constants in the above equation (5) are calculated as follows:

$$
\mathrm{A}_{\mathrm{i}}=\mathrm{e}^{-\mathrm{n}_{\mathrm{i}} \cdot \Delta \hat{\mathrm{t}}} ; \mathrm{B}_{\mathrm{i}}=\frac{\mathrm{m}_{\mathrm{i}}}{\Delta \hat{\mathrm{t}} \cdot \mathrm{n}_{\mathrm{i}}} \cdot\left[1-\mathrm{A}_{\mathrm{i}}\right] ; \mathrm{C}_{\mathrm{i}}=\mathrm{A}_{\mathrm{i}} \cdot \mathrm{B}_{\mathrm{i}}
$$

where $n_{i}$ and $m_{i}$ - coefficients describing the effective weighting functions, $\Delta \hat{\mathrm{t}}-$ dimensionless time step.

Simulations implemented in this project on a large scale were designed to determine:

A) The effect of the method of calculating wall shear stress using the method of characteristics. Numerical research was carried out using the standard method SM (shear stress calculated at each numerical node using equation (5)) and the simplified method LFM (full calculation only in boundary nodes) [8], in which the shear stress in all internal nodes of the grid of characteristics is calculated using a simple quasi-steady formula:

$$
\tau_{w(t+\Delta t)}=\frac{\rho \lambda_{(t+\Delta t)} \mathrm{V}_{(t+\Delta t)}\left|\mathrm{V}_{(t+\Delta t)}\right|}{8}
$$

B) The impact of the construction and the scope of the effective weighting functions applicability on the results obtained. In particular, simple functions composed of only two and three exponential expressions (Fig. 1) were tested. For comparison, a highly accurate function, consisting of 10 exponential expressions, was also estimated. All functions were estimated using the method presented in [20]. In the numerical process, the coefficients of these estimated functions were scaled using assumptions about their universality [17]. Specific values of the coefficients are listed in the Appendix.

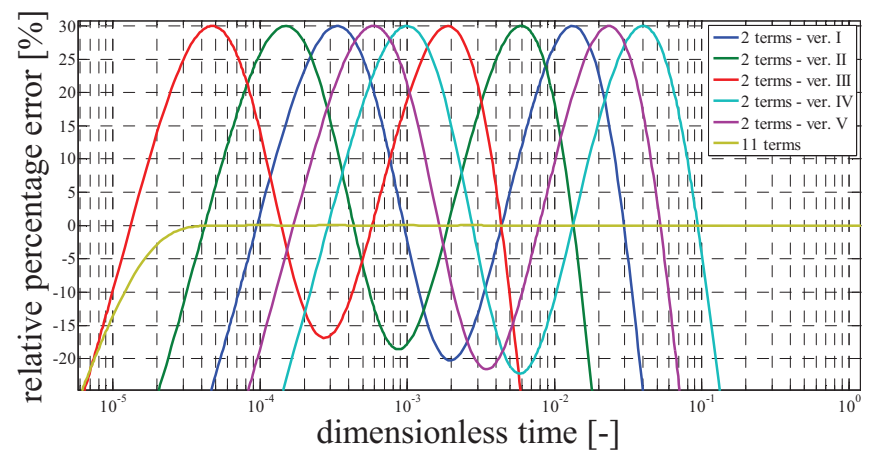

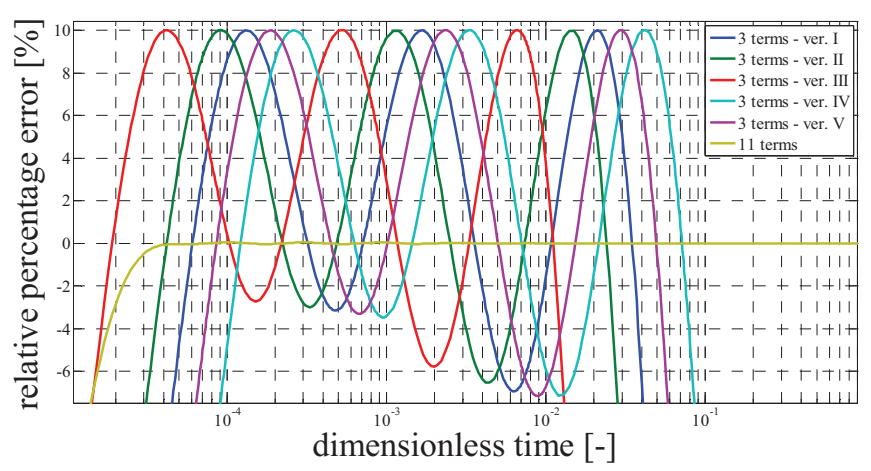

Fig. 1. Errors of the estimated effective weighting functions

C) The impact of the initial flow velocity. Detailed tests were carried out for six pressure fluctuation cases (initial flow velocities: $0.45 \mathrm{~m} / \mathrm{s}, 0.82 \mathrm{~m} / \mathrm{s}, 1.02 \mathrm{~m} / \mathrm{s}, 1.7 \mathrm{~m} / \mathrm{s}, 1.9 \mathrm{~m} / \mathrm{s}$, $2.76 \mathrm{~m} / \mathrm{s}$ ), which are the result of a sudden shut off of flow by closing a valve in a simple hydraulic system (used experimental results are described in the works by Adamkowski and Lewandowski $[2,3]$ ).

In total, as a result of examination of the impact of the aforementioned three decisive factors (simulation methods, the shape of the eff. weighting function and initial velocity), a series of numerical tests has been implemented, consisting of as many as one hundred and thirty-two computer simulations (Fig. 2).

\begin{tabular}{ccccc|c} 
METHODS & EFF. WEIGHTING FUNCTION & CASES & $\begin{array}{l}\text { TOTAL NUMBER } \\
\text { OF SIMULATION }\end{array}$ \\
\hline 2 & $*$ & 11 & $*$ & 6 & $=132$
\end{tabular}

Fig. 2. Number of simulations

Since the pressure decreased in most simulations to the vapor pressure, the cavitation model according to Adamkowski and Lewandowski [1] has been used. Using this model, in general situation for pipe segment filled with liquid and vaporous zones discretely distributed along its length in several sections (Fig. 3), shifting of cavity volumes from intermediate zones to the main vaporous zone are needed. The equations for mean velocities calculated in all cross sections of pipe in which the cavity volumes where moved to the main vapor cavity is:

$$
\begin{aligned}
& \mathrm{v}_{\mathrm{j}}=\operatorname{sgn}\left[0.5\left(\mathrm{v}_{\mathrm{j}}^{+}\left|\mathrm{v}_{\mathrm{j}}^{+}\right|+\mathrm{v}_{\mathrm{j}}^{-}\left|\mathrm{v}_{\mathrm{j}}^{-}\right|\right)+\Delta \mathrm{Z}_{\mathrm{i}}\right] . \\
& \sqrt{\left|0.5\left[\left(\mathrm{v}_{\mathrm{j}}^{+}\right)^{2}+\left(\mathrm{v}_{\mathrm{j}}^{-}\right)^{2}\right]+\Delta \mathrm{Z}_{\mathrm{i}}\right|}
\end{aligned}
$$

where:

$$
\begin{aligned}
& \text { for } \mathrm{j}<\mathrm{k}: \quad \Delta \mathrm{Z}_{\mathrm{i}}=\mathrm{g} \sum_{\mathrm{i}=1}^{\mathrm{j}}\left(\mathrm{V}_{\text {cav }, \mathrm{i}} \sin \beta_{\mathrm{i}}\right) / \mathrm{A}_{\mathrm{i}} \\
& \text { for } \mathrm{j}>\mathrm{k}: \quad \Delta \mathrm{Z}_{\mathrm{i}}=\mathrm{g} \sum_{\mathrm{i}=\mathrm{j}}^{\mathrm{n}}\left(\mathrm{V}_{\text {cav }, \mathrm{i}} \sin \beta_{\mathrm{i}}\right) / \mathrm{A}_{\mathrm{i}}
\end{aligned}
$$

For the main vapor cavity the velocities at the left and right sides are calculated using equations: 


$$
\left\{\begin{array}{l}
\mathrm{v}_{\mathrm{k}}^{-}{ }^{\prime}=\operatorname{sgn}\left[\mathrm{v}_{\mathrm{k}}^{-}\left|\mathrm{v}_{\mathrm{k}}^{-}\right|+2 \Delta \mathrm{Z}_{\mathrm{j}-}\right] \sqrt{\left|\left(\mathrm{v}_{\mathrm{k}}^{-}\right)^{2}+2 \Delta \mathrm{Z}_{\mathrm{j}-}\right|} \\
\mathrm{v}_{\mathrm{k}}^{+}{ }^{\prime}=\operatorname{sgn}\left[\mathrm{v}_{\mathrm{k}}^{+}\left|\mathrm{v}_{\mathrm{k}}^{+}\right|+2 \Delta \mathrm{Z}_{\mathrm{j}+}\right] \sqrt{\left|\left(\mathrm{v}_{\mathrm{k}}^{+}\right)^{2}+2 \Delta \mathrm{Z}_{\mathrm{j}+}\right|}
\end{array}\right.
$$

where:

$$
\begin{aligned}
& \Delta \mathrm{Z}_{\mathrm{j}-}=\mathrm{g} \sum_{\mathrm{j}=1}^{\mathrm{k}-1}\left(\mathrm{~V}_{\mathrm{cav}, \mathrm{j}} \sin \beta_{\mathrm{j}}\right) / \mathrm{A}_{\mathrm{j}} \text { and } \\
& \Delta \mathrm{Z}_{\mathrm{j}+}=\mathrm{g} \sum_{\mathrm{j}=\mathrm{k}+1}^{\mathrm{n}}\left(\mathrm{V}_{\mathrm{cav}, \mathrm{j}} \sin \beta_{\mathrm{j}}\right) / \mathrm{A}_{\mathrm{j}}
\end{aligned}
$$

For each executed simulation, for the purpose of simple quantitative reasoning, two parameters were determined representing the error of compatibility of the simulated pressure run with the experimental one.

The first parameter represents the mean absolute percentage error of simulated maximum pressure values on the subsequent pressure amplitudes (Fig. 4). It is calculated from the following simple formula:

$$
\mathrm{Ep}=\frac{\sum_{\mathrm{i}=1}^{\mathrm{k}}\left|\frac{\mathrm{p}_{\mathrm{is}}-\mathrm{p}_{\mathrm{ie}}}{\mathrm{p}_{\mathrm{ie}}}\right| \cdot 100 \%}{\mathrm{k}}
$$

where: $\mathrm{k}$ - number of analyzed pressure amplitudes, $\mathrm{p}_{\mathrm{is}}$ the maximum pressure on the $\mathrm{i}$-th analyzed amplitude in the simulated graph; $\mathrm{p}_{\mathrm{ie}}-$ the maximum pressure on the $i$-th analyzed amplitude in the experimental graph.
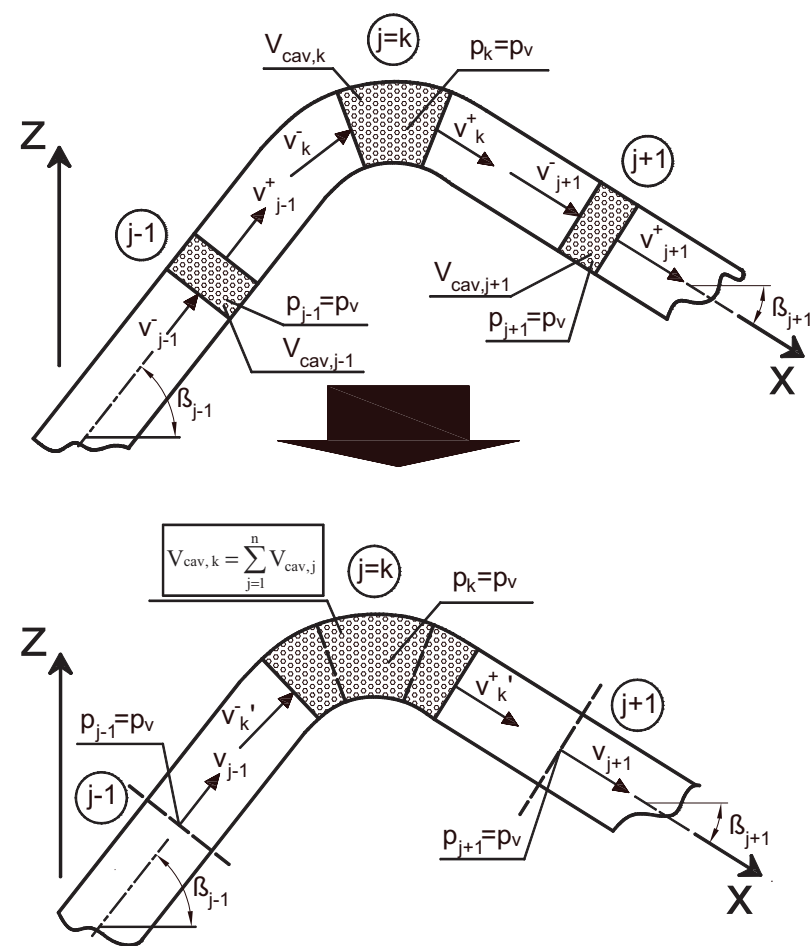

Fig. 3. Schematic diagram of the Adamkowski-Lewandowski model [1]
The second parameter describes the mean absolute percentage error for the time of occurrence of consecutive pressure peaks (Fig. 4). It is calculated similarly:

$$
\mathrm{Et}=\frac{\sum_{\mathrm{i}=1}^{\mathrm{k}}\left|\frac{\mathrm{t}_{\mathrm{is}}-\mathrm{t}_{\mathrm{ie}}}{\mathrm{t}_{\mathrm{ie}}}\right| \cdot 100 \%}{\mathrm{k}}
$$

where $t_{\text {is }}$ - time of occurrence of the maximum pressure on the i-th analyzed amplitude from the the simulated graph; $t_{i e}$ - time of occurrence of the maximum pressure on the $i$-th analyzed amplitude from the experimental graph.

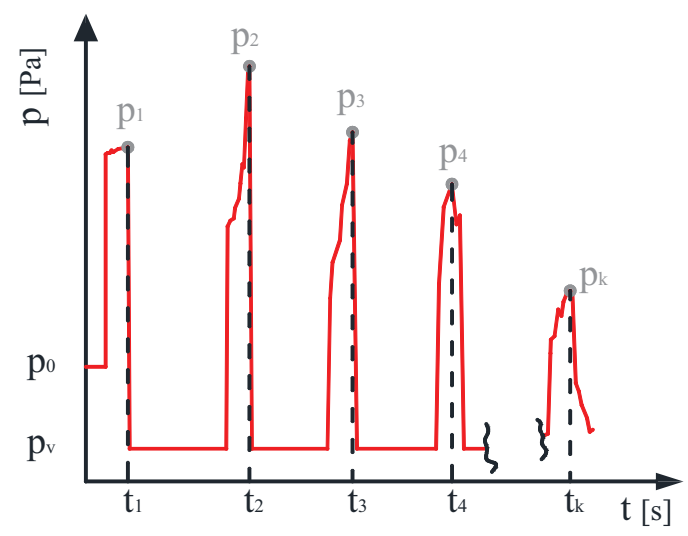

Fig. 4. Analyzed pressure values in the quantitative method

The smaller the values of the above parameters Ep and Et, the better was the accuracy of the simulation.

For better readability of next chapter, it is worth to present an example comparison (Fig. 5) of the simulated pressure run with the experimental one. Achieved result were received using a standard model of SM computation for a case with initial liquid velocity $\mathrm{v}_{0}=2.76 \mathrm{~m} / \mathrm{s}$ and effective weighting function in ver. 5 . Such comparisons enabled the determination of the parameters Ep and Et analyzed in details in following subchapter.

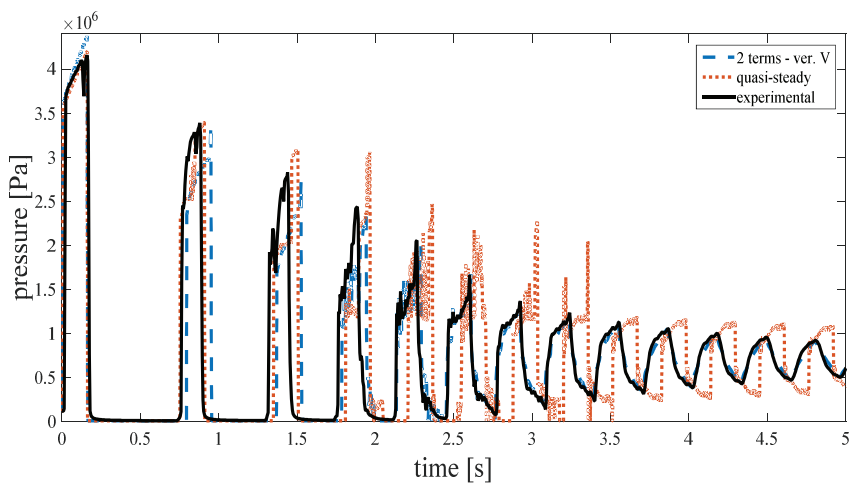

Fig. 5. Examples of the results of simulations 


\section{DISCUSSION OF SIMULATIONS RESULTS}

The results of the numerous simulations are presented in the following group charts (Fig. 6, Fig.7). Fig. 6a features the results which show the change in the relative percentage error Ep for the analyzed effective functions composed of only two exponential expressions at different initial velocities of unsteady flow and when the simulations were performed using the standard method. It can be seen that good results, with a low value of the Ep parameter (less than $10 \%)$, were obtained for low flow velocities $\left(\mathrm{v}_{0}=0.45 \mathrm{~m} / \mathrm{s}\right.$ and $\mathrm{v}_{0}=0.82 \mathrm{~m} / \mathrm{s}$ ) using ver. IV of the weighting function. A little worse results using this function in comparison with other results were reported by simulating the flow starting at higher flow rates - an error of about 5 percent for the initial velocity equal to $1.02,1.7,1.9$, and 2.76 meters per second. To unambiguously determine which version of two-terms effective weighting function during simulations carried out using the classical method (determination of quasi-steady and unsteady components of shear stress in all nodes of the grid of characteristics along the length of the pipe) has a minimal error, the errors obtained for different flow velocities were added (Tab. 1).

Tab. 1. Sum of errors parameters for 2 terms functions (for all $v_{0}$ cases: 0.45, $0.82,1.02,1.7,1.9,2.76$ )

\begin{tabular}{|c|c|c|c|c|}
\hline \multirow{2}{*}{$\begin{array}{c}\text { Type of weighting } \\
\text { function }\end{array}$} & \multicolumn{2}{|c|}{$\begin{array}{c}\text { Standard unsteady } \\
\text { friction - SM }\end{array}$} & \multicolumn{2}{c|}{$\begin{array}{c}\text { Lumped unsteady } \\
\text { friction - LFM }\end{array}$} \\
\cline { 2 - 5 } & $\mathbf{\Sigma E t}$ & $\boldsymbol{\Sigma E p}$ & $\boldsymbol{\Sigma E t}$ & $\boldsymbol{\Sigma} \mathrm{Ep}$ \\
\hline 2 terms - v. I & 19,84 & 55,29 & 14,63 & 48,79 \\
\hline 2 terms - v. II & 17,02 & 48,26 & 14,55 & 54,87 \\
\hline 2 terms - v. III & 15,51 & 42,66 & 13,89 & 44,65 \\
\hline 2 terms - v. IV & $\mathbf{1 5 , 3 9}$ & 38,31 & 16,26 & 40,94 \\
\hline 2 terms - v. V & 17,24 & 42,57 & 14,03 & 37,68 \\
\hline
\end{tabular}

According to the data from the above table, the assumptions resulting from the qualitative analysis of the curves in Fig. 6a are confirmed. During standard numerical simulations using the effective weighting function composed of two exponential expressions, ver. 4 of the weighting function

a) 2 TERMS - SM

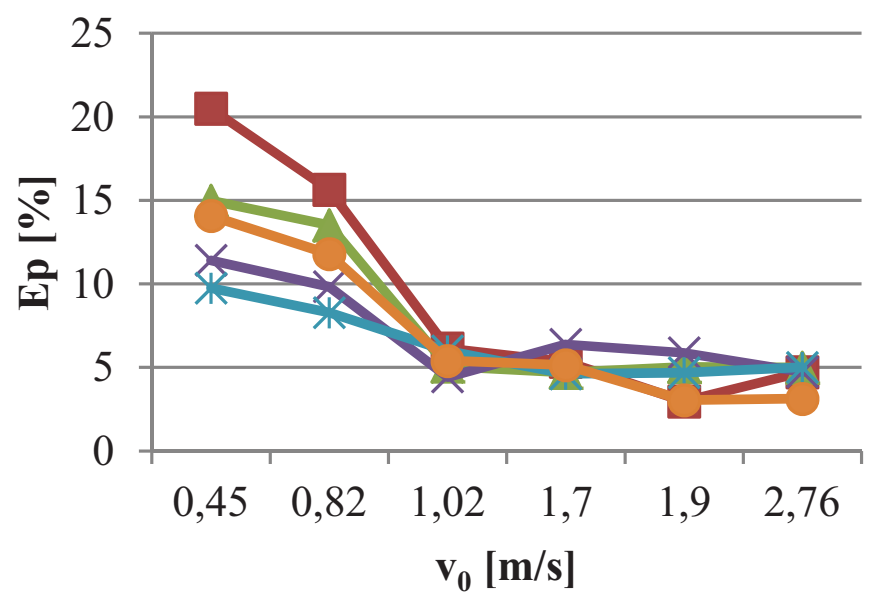

b) 2 TERMS - LFM

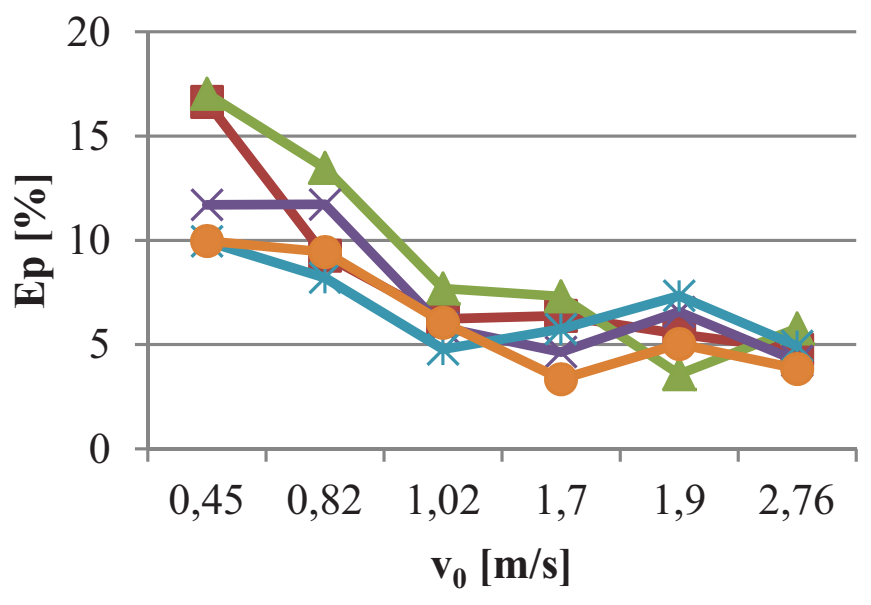

c) 3 TERMS - SM

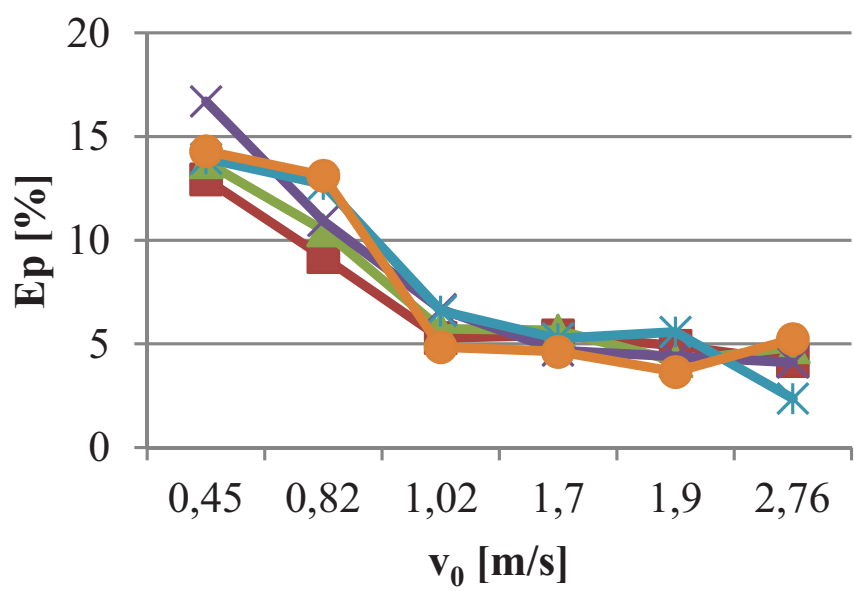

d) 3 TERMS - LFM
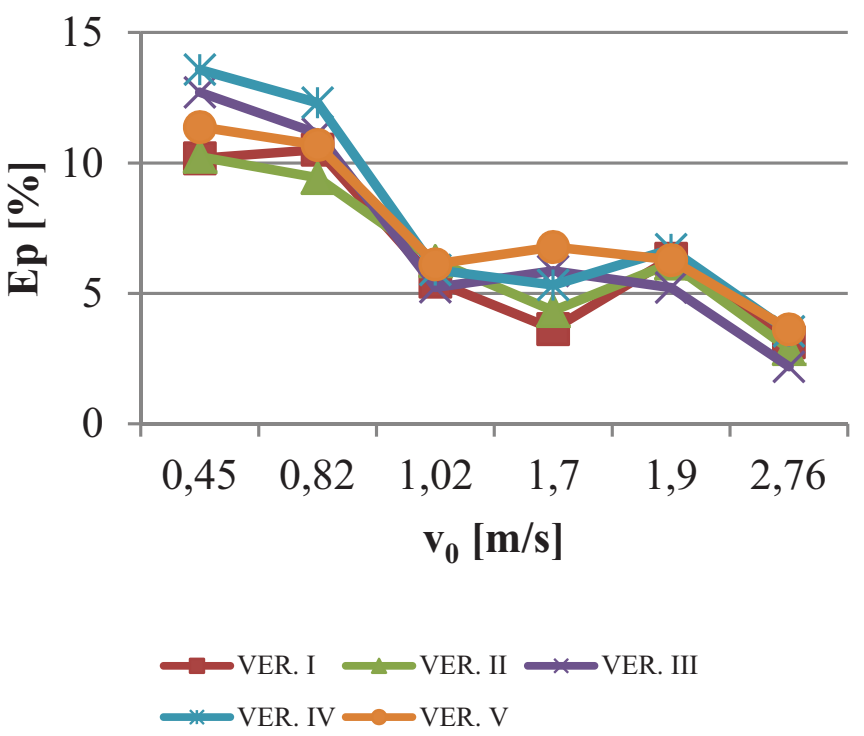

Fig. 6. Results of $\mathbf{E p}[\%]$ variation

$(\Sigma \mathrm{Ep}=\mathbf{3 8 . 3 1 \%})$ turned out to be the best. This result was, what is worth noting, as much as $6.1 \%$ lower than the summary 
result obtained for a very precise effective 10-expression weighting function (Tab. 2).

Tab. 2. Sum of errors parameters for 10 terms function (for all $v_{0}$ cases: 0.45 , $0.82,1.02,1.7,1.9,2.76$ )

\begin{tabular}{|c|c|c|c|c|}
\hline \multirow{2}{*}{$\begin{array}{l}\text { Type of } \\
\text { weighting } \\
\text { function }\end{array}$} & \multicolumn{2}{|c|}{$\begin{array}{c}\text { Standard unsteady } \\
\text { friction - SM }\end{array}$} & \multicolumn{2}{|c|}{$\begin{array}{l}\text { Lumped unsteady } \\
\text { friction - LFM }\end{array}$} \\
\hline & $\sum E t$ & $\Sigma E p$ & $\Sigma E t$ & $\Sigma \mathrm{Ep}$ \\
\hline 10 terms & 17,64 & 44,41 & 16,51 & 51,47 \\
\hline
\end{tabular}

The results indicate that the amount of components is not responsible for the quality of the estimation of the maximum pressure (occurring in successive amplitudes of pressure graphs which are the results of water hammer) as well as the time of their emergence, as confirmed by the data related to the Et parameters included in Tab. 1 and Tab. 2.

Then, analyzing the results shown in Fig. $6 \mathrm{~b}$, it seems that even better results were obtained using the effective weighting function composed of two expressions marked as ver. 5, in combination with the method focusing non-stationary components of wall shear stress only in the boundary nodes of the pipe (at the inlet and outlet - Johnston's method [8]). The total estimation error of the maximum pressure for all analyzed graphs amounted to $\Sigma \mathbf{E p}=\mathbf{3 7 . 6 8 \%}$ (Tab. 1). Interestingly, this result was lower than that obtained using the very precise effective weighting function (10-component) for this series of tests, up to approx. $13 \%$. This clearly confirms the need for using simple weighting functions instead of multi-expression ones representing a high correlation with the classical weighting functions (according to Zielke [26] or Vardy-Brown [21-23]) and additionally it supports not accounting for unsteady resistance in the internal nodes.

The analysis of plots for the same simulations but using more accurate weighting functions composed of three exponential expression is shown in Fig. $6 \mathrm{c}$ and Fig. 6d. On the basis of Fig. $6 c$, it can be expected that the best results were obtained using the effective weighting function composed of three exponential expressions in ver. I when the calculations were performed by standard computing. In contrast, when the calculations were carried out by focusing the unsteady resistance only in the boundary nodes of the grid of characteristics, it can be concluded from Fig. $6 \mathrm{~d}$ that the smallest errors were found in the simulations using the 3-expression effective weighting function in ver. II. Additionally, analyzing the quality results obtained by using functions composed of three expressions (Fig. $6 \mathrm{c}$ and Fig. $6 \mathrm{~d}$ ) and the results for the two-component functions (Fig. 6a and Fig. 6b) it can be seen that in the case of a more accurate functions (with 3 expressions), dispersion error for equal initial flow velocities and different used versions of the weighting function is smaller. Thus, it seems that in this case a slightly better matching of the simulated results to the experimental ones should occur. However, the analysis from Tab. 3 with the final quantitative results does not confirm the last conclusion made regarding the better compliance, because the results for the Ep parameters obtained with the weighting function which is the best for modelling maximum pressure
- ver. I (both in standard and lumped simulation - Tab. 3) are slightly higher than the best ones obtained using the effective 2-expression functions (Tab. 1). Using the solutions lumping the resistances in boundary nodes, we can also see that very good results are obtained using the 3-component weight function in ver. II (Tab. 3).

Tab. 3. Sum of errors parameters for 3 terms functions (for all $v_{0}$ cases: 0.45, $0.82,1.02,1.7,1.9,2.76)$

\begin{tabular}{|c|c|c|c|c|}
\hline \multirow{2}{*}{$\begin{array}{l}\text { Type of weighting } \\
\text { function }\end{array}$} & \multicolumn{2}{|c|}{$\begin{array}{l}\text { Standard unsteady } \\
\text { friction - SM }\end{array}$} & \multicolumn{2}{|c|}{$\begin{array}{l}\text { Lumped unsteady } \\
\text { friction - LFM }\end{array}$} \\
\hline & $\Sigma E t$ & $\Sigma E p$ & $\Sigma E t$ & $\Sigma$ Ep \\
\hline 3 terms - v. I & 16,1 & 41,91 & 14,91 & 39,23 \\
\hline 3 terms - v. II & 16,47 & 44,62 & 14,3 & 39,26 \\
\hline 3 terms - v. III & 17,68 & 47,46 & 15,59 & 42,34 \\
\hline 3 terms - v. IV & 16,09 & 46,42 & 14,95 & 47,34 \\
\hline 3 terms $-\mathrm{v} . \mathrm{V}$ & 15,96 & 45,76 & 15,2 & 44,87 \\
\hline
\end{tabular}

The above presented analysis showed no significant influence of the number of exponential expressions (thus decreasing the degree of compliance with the exact weighting function) on the final results of changes in the pressure graph.

The results presented in figure 7 illustrate the variation of the coefficient $\mathbf{E t}$, the responsibility of which is to determine the time (phase) compliance of simulate pressure amplitudes. It can be seen from them that it is difficult to identify one weighting function (among 10 analyzed ones: 2 terms ver. I-V, 3 terms - ver. I-V), as well as one method of friction modelling (SM, LFM) from which the best simulation results are being obtained.

However, it can be clearly concluded that the dispersion of the obtained results is much smaller at the time of applying more accurate effective weighting functions being constructed from three terms (this is particularly visible in Fig. 7c).

The maximum Et errors in the performed simulations being analyzed occurred in the modelled courses with the initial velocities $\mathrm{v}_{0}=1.7 \mathrm{~m} / \mathrm{s}$ and $\mathrm{v}_{0}=1.9 \mathrm{~m} / \mathrm{s}$. Interestingly, the results being obtained in the course with the highest initial velocity $\mathrm{v}_{0}=2.76 \mathrm{~m} / \mathrm{s}$ were characterized by a decrease in the Et error.

a) 2 TERMS - SM

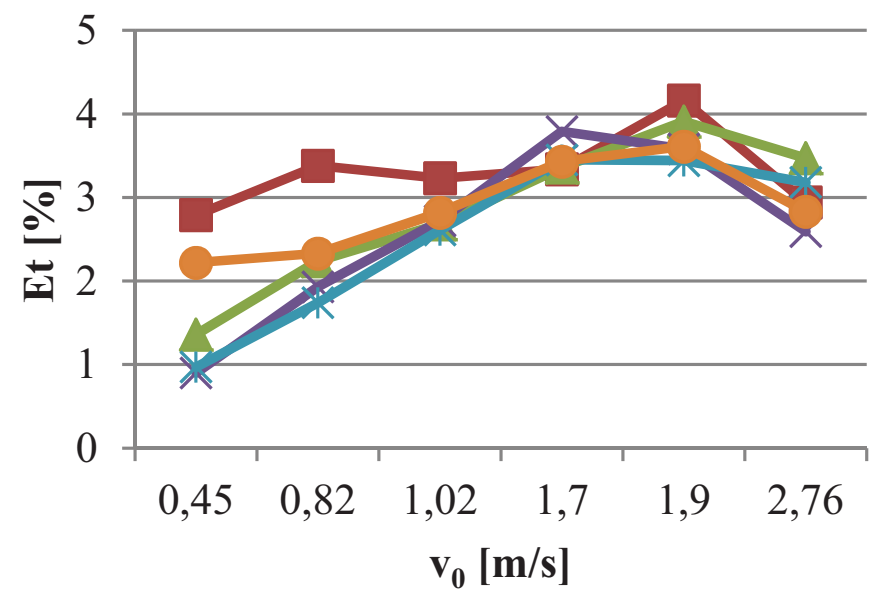


b) 2 TERMS - LFM

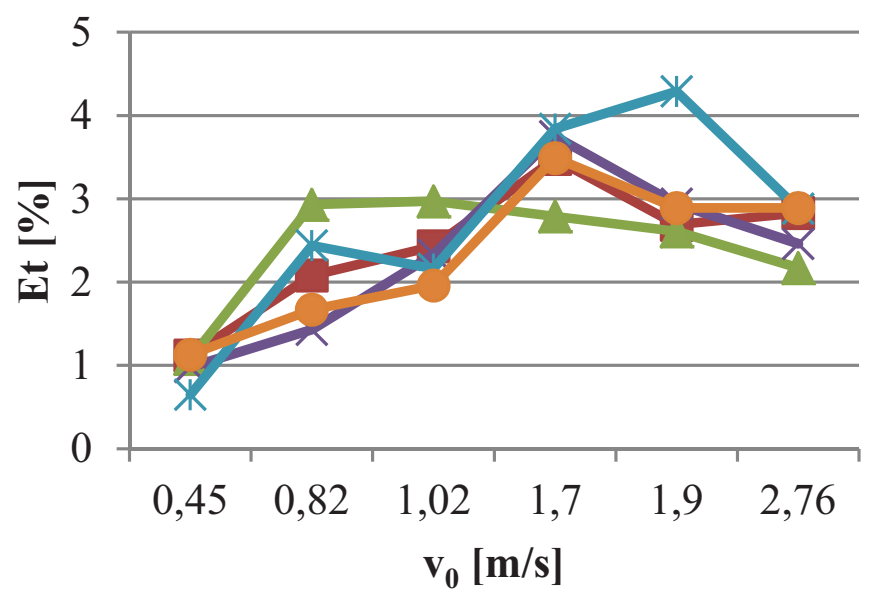

c) 3 TERMS - SM

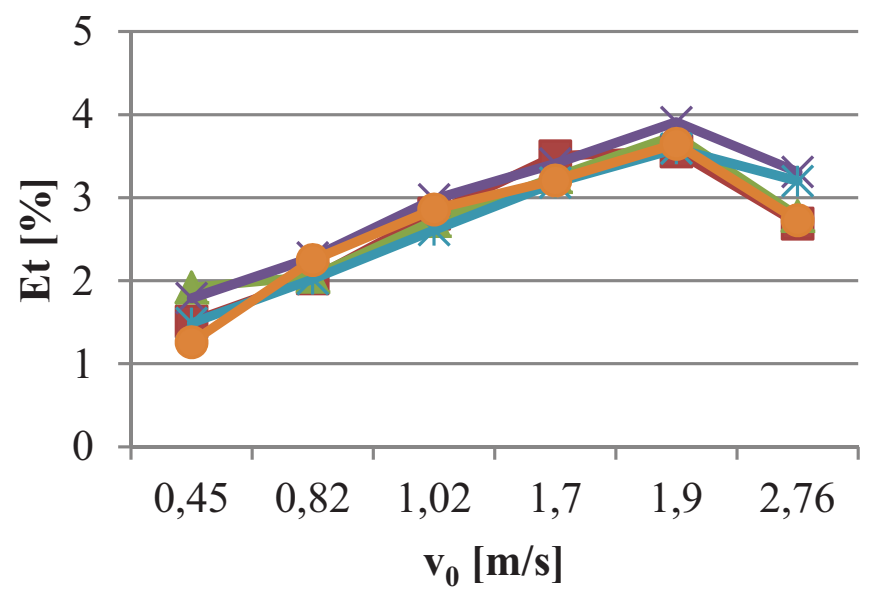

d) 3 TERMS - LFM
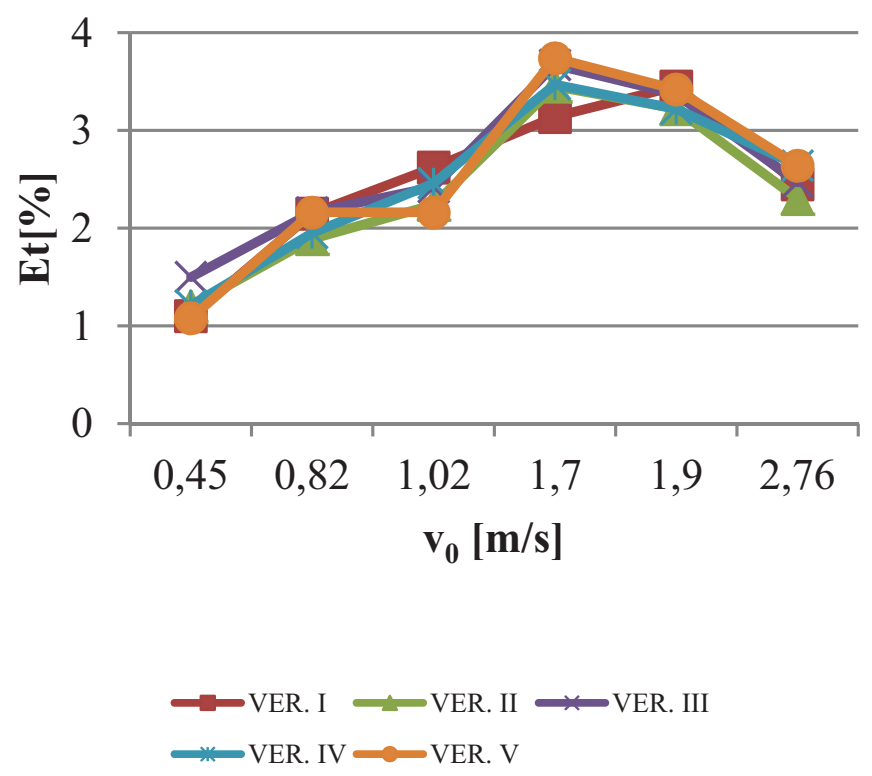

Fig. 7. Results of $\boldsymbol{E} \boldsymbol{t}[\%]$ variation

It is possible that it has something to do with a decreasing importance of unsteady shear stress $\tau_{\mathrm{u}}$ together with the increasing Reynolds number. It is therefore unfortunate that the tests were not accomplished within a broader range of Reynolds numbers (range from 40000 to 100000) as the analysis of such results would allow for a wider verification of the above formulated hypothesis. The error variation itself may be considered independent of the applied weighting function ( 2 terms or 3 terms), as well as of the used method of resistance modelling (SM or LFM), because the course illustrating the distribution of errors in the function of change in the initial velocity of flow is very similar (Fig. 7a - Fig. 7d).

When comparing qualitatively the results obtained for the SM model only, it can be seen that final errors for 2 and 3 term weighting functions in version IV (having the same range of application in the domain of dimensionless time) are very similar with a slight predominance of two term weighting function (see: Fig. 7a, Fig. 7c and Tab. 1, Tab. 3).

When using the LFM model, good results were obtained (Fig. 7b) applying 2 term weighting function - ver. II because the Et error was below 3\% for all accomplished simulations. Unfortunately, for the courses with low initial velocities (from $\mathrm{v}_{0}=0.45$ up to $\mathrm{v}_{0}=1.02 \mathrm{~m} / \mathrm{s}$ ) it was much greater than applying other weighting functions. When looking at the quantitative results (Tab. 1 and Tab. 3), it can be seen that cumulatively 2 term weighting function in ver. III and 3 term weighting function in ver. II, respectively, were characterized by the smallest errors in these simulations with the use of the LFM model.

To determine the stability of the results obtained depending on the number of exponential expressions representing the effective weighting function, the distribution of errors $\mathrm{R}_{\mathrm{Et}}$ and $R_{\text {Ер }}$ was calculated for all the tests carried out (Tab. 4 and Tab. 5):

$$
\mathrm{R}_{\mathrm{Et}}=\mathrm{Et}_{\max }-\mathrm{Et}_{\min } \text { and } \quad \mathrm{R}_{\mathrm{Ep}}=\mathrm{Ep}_{\max }-\mathrm{Ep}_{\min }
$$

The tables presented below show that:

- increasing the number of exponential expressions affects the stability of the solutions, as there is a significant decline in the value of errors distribution for three-component weighting functions;

- the use of the method concentrating unsteady expression of friction in the boundary nodes of the grid of characteristics in the graphs with low Reynolds numbers $\left(\mathrm{v}_{0}=0.45\right.$ and $\left.\mathrm{v}_{0}=0.82\right)$ increases the stability of the solutions as it reduces the value of the distribution. At higher Reynolds numbers, however, there was a slight increase in the distribution when applying this simplified method.

Tab. 4. Range of error Et results

\begin{tabular}{|c|c|c|c|c|}
\hline \multirow{2}{*}{$\mathbf{v}_{\mathbf{0}}[\mathbf{m} / \mathbf{s}]$} & \multicolumn{2}{|c|}{$\begin{array}{c}\text { 2 terms weighting } \\
\text { functions } \mathbf{R}_{\mathrm{Et}}[\%]\end{array}$} & \multicolumn{2}{c|}{$\begin{array}{c}\text { 3 terms weighting } \\
\text { functions } \mathbf{R}_{\mathrm{Et}}[\%]\end{array}$} \\
\cline { 2 - 5 } & $\mathbf{S M}$ & LFM & $\mathbf{S M}$ & LFM \\
\hline $\mathbf{0 . 4 5}$ & 1.89 & 0.48 & 0.66 & 0.42 \\
\hline $\mathbf{0 . 8 2}$ & 1.64 & 1.5 & 0.26 & 0.27 \\
\hline $\mathbf{1 . 0 2}$ & 0.62 & 1.01 & 0.37 & 0.46 \\
\hline $\mathbf{1 . 7}$ & 0.45 & 1.05 & 0.32 & 0.60 \\
\hline
\end{tabular}




\begin{tabular}{|c|c|c|c|c|}
\hline \multirow{2}{*}{$\mathbf{v}_{\mathbf{0}}[\mathbf{m} / \mathbf{s}]$} & \multicolumn{2}{|c|}{$\begin{array}{c}\text { 2 terms weighting } \\
\text { functions } \mathbf{R}_{\mathrm{Et}}[\%]\end{array}$} & \multicolumn{2}{c|}{$\begin{array}{c}\text { 3 terms weighting } \\
\text { functions } \mathbf{R}_{\mathrm{Et}}[\%]\end{array}$} \\
\cline { 2 - 5 } & $\mathbf{S M}$ & LFM & SM & LFM \\
\hline $\mathbf{1 . 9}$ & 0.72 & 1.68 & 0.35 & 0.23 \\
\hline $\mathbf{2 . 7 6}$ & 0.88 & 0.72 & 0.62 & 0.34 \\
\hline
\end{tabular}

Tab. 5. Range of error Ep results

\begin{tabular}{|c|c|c|c|c|}
\hline \multirow{2}{*}{$\mathbf{v}_{\mathbf{0}}[\mathbf{m} / \mathbf{s}]$} & \multicolumn{2}{|c|}{$\begin{array}{c}\text { 2 terms weigting } \\
\text { functions } \mathbf{R}_{\mathrm{Ep}}[\%]\end{array}$} & \multicolumn{2}{c|}{$\begin{array}{c}\text { 3 terms weighting } \\
\text { functions } \mathbf{R}_{\mathrm{Ep}_{\mathrm{p}}}[\%]\end{array}$} \\
\cline { 2 - 5 } & $\mathbf{S M}$ & $\mathbf{L F M}$ & $\mathbf{S M}$ & $\mathbf{L F M}$ \\
\hline $\mathbf{0 . 4 5}$ & 10.74 & 7.08 & 3.76 & 3.40 \\
\hline $\mathbf{0 . 8 2}$ & 7.35 & 5.27 & 3.93 & 2.88 \\
\hline $\mathbf{1 . 0 2}$ & 1.71 & 2.92 & 1.83 & 1.01 \\
\hline $\mathbf{1 . 7}$ & 1.77 & 3.97 & 1.02 & 3.15 \\
\hline $\mathbf{1 . 9}$ & 2.91 & 3.76 & 1.92 & 1.47 \\
\hline $\mathbf{2 . 7 6}$ & 1.87 & 1.94 & 2.87 & 1.43 \\
\hline
\end{tabular}

As can be concluded from the tests conducted, further research is necessary to enable the easy calculation of the coefficients in effective two-component weight functions: $\mathrm{m}_{1}, \mathrm{~m}_{2}, \mathrm{n}_{1}$ and $\mathrm{n}_{2}$.

\section{CONCLUSIONS}

The simplified method of estimating the instantaneous wall shear stress presented in the paper is an important issue when solving equations describing unsteady fluid flow in pressure lines. The presented solution increases the speed of calculations while maintaining the necessary accuracy for estimating the pressure runs. At the moment, it is becoming possible to estimate the pressure variations occurring in simple systems in real time - which gives great opportunities for the design of control systems.

The series of numerical tests carried out as part of this project proved that:

a) the effective weighting functions need not be composed of multiple components and thus represent a high correlation with the classical functions (Zielke or those from VardyBrown). Proper modelling of wall shear stress is obtained using two components,

b) the simplified method concentrating unsteady friction only in boundary nodes can be successfully used,

c) gentle shift of the lower limit of the applicability of the effective weighting function affects the simulated results. However, at the present stage of research it would be hard to look for any distinct trend.

Another problem, which should be addressed in the near future has been revealed by the analysis of the courses of Ep errors obtained in the simulations carried out (Fig. 6). Model of unsteady flow with cavitation according to Adamkowski and Lewandowski [1] used in this paper, with too large error (about 10\%), models the flows in the range of low Reynolds numbers $\left(\mathrm{v}_{0}=0.45 \mathrm{~m} / \mathrm{s}\right.$ and $\left.\mathrm{v}_{0}=0.82 \mathrm{~m} / \mathrm{s}\right)$. Therefore, it requires modifications in order to more accurately simulate the transitional flows. Probably, the inclusion of gas cavitation (and not just vapor cavitation) will allow for a significant improvement in the quality of the modelled functions.

Lack of a detailed definition of an optimal lower range of applicability (for low dimensionless times) for the effective weighting function forces the implementation of further quantitative research. Without a clearly defined optimal lower limit of the applicability for the effective weighting functions, it is not possible to optimize the process of safe automatic control of hydraulic systems.

\section{ACKNOWLEDGMENT}

Some part of this work was presented at the 12th International Conference on Pressure Surges, 18-20 November 2015, Dublin, Ireland

\section{BIBLIOGRAPHY}

1. Adamkowski A., Lewandowski M.: A new method for numerical prediction of liquid column separation accompanying hydraulic transients in pipelines, J. Fluids Eng., 131, 7, 2009.

2. Adamkowski A., Lewandowski M.: Experimental examination of unsteady friction models for transient pipe flow simulation, J. Fluids Eng., 128, pp. 1351-1363, 2006.

3. Adamkowski A., Lewandowski M.: Investigation of hydraulic transients in a pipeline with column separation, J. Hydraulic Eng., 138, 11, pp. 935-944, 2012.

4. Górski Z.: Construction and operation of marine hydraulic machinery, Trademar, Gdynia, 2008.

5. Hadj-Taïeb L., Hadj-Taïeb E.: Modelling vapour cavitation in pipes with fluid-structure interaction, International Journal of Modelling and Simulation, 29, 3, pp. 263-270, 2009

6. Hadj-Taïeb L., Hadj-Taïeb E.: Numerical simulation of transient flows in viscoelastic pipes with vapour cavitation, International Journal of Modelling and Simulation, 29, 2, pp. 206-213, 2009.

7. Henclik S.: A numerical approach to the standard model of water hammer with fluid-structure interaction, Journal of Theoretical and Applied Mechanics, 53, 3, pp. 543-555, 2015.

8. Johnston D.N.: Efficient methods for numerical modelling of laminar friction in fluid lines. J. Dynamic Systems Measurement and Control, ASME, 128, 4, pp. 829 - 834, 2006. 
9. Karadžić U. et al.: Valve-induced water hammer and column separation in a pipeline apparatus, Strojniški Vestnik Journal of Mechanical Engineering, 60, 11, pp. 742-754, 2014.

10. Keramat A. et al.: Fluid-structure interaction with pipe-wall viscoelasticity during water hammer, Journal of Fluids and Structures, 28, 1, pp. 434-456, 2012.

11. Pezzinga G.: Evaluation of time evolution of mechanical parameters of polymeric pipes by unsteady flow runs, Journal of Hydraulic Engineering, 140, 12, paper 04014057, 2014.

12. Qiu Y. et al.: Suppressing water hammer of ship steering systems with hydraulic accumulator. Proc IMechE Part E: J Process Mechanical Engineering, Vol. 228 (2), pp. 136-148, 2014

13. Reddy H.P. et al.: Estimation of decay coefficients for unsteady friction for instantaneous, acceleration-based models, Journal of Hydraulic Engineering, 138, pp. 260271,2012

14. Soares A.K. et al.: Investigation of transient vaporous cavitation: experimental and numerical analyses, Procedia Engineering, 119, pp. 235-242, 2015.

15. Storli P., Nielsen T.: Transient friction in pressurized pipes. I: investigation of Zielke's model, Journal of Hydraulic Engineering, 137, 5, pp. 577-584, 2011.

16. Storli P., Nielsen T.: Transient friction in pressurized pipes. II: two-coefficient instantaneous acceleration-based model, Journal of Hydraulic Engineering, 137, 6, pp. 679-695, 2011.

17. Urbanowicz, K. et al.: Universal weighting function in modeling transient cavitating pipe flow, J. Theoretical and Applied Mechanics, 50, 4, pp. 889-902, 2012.

18. Urbanowicz, K., Zarzycki, Z.: Convolution Integral in Transient Pipe Flow, Proc. of the XXth Fluid Mechanics Conference KKMP2012, Gliwice, Poland, 17-20 September, on CD, 2012.

19. Urbanowicz, K., Zarzycki, Z.: Improved lumping friction model for liquid pipe flow, J. Theoretical and Applied Mechanics, 53, 2, pp. 295-305, 2015.

20. Urbanowicz, K.: New approximation of unsteady friction weighting functions. Proc. of the 11th International Conference on Pressure Surges, Lisbon, Portugal, October 24-26, pp. $477-492,2012$.

21. Vardy, A.E., Brown, J.M.B.: Approximation of turbulent wall shear stresses in highly transient pipe flows, Journal of Hydraulic Engineering, 133, 11, pp. 1219-1228, 2007.
22. Vardy, A.E., Brown, J.M.B.: Transient turbulent friction in fully rough pipe flows, Journal of Sound and Vibration, 270, pp. 233-257, 2004.

23. Vardy, A.E., Brown, J.M.B.: Transient turbulent friction in smooth pipe flows, Journal of Sound and Vibration, 259, pp. 1011-1036, 2003.

24. Wylie, E.B., Streeter, V.L.: Fluid transients in systems, Prentice-Hall Inc., Englewood Cliffs, New Jersey, 1993.

25. Zanganeh R. et al.: Fluid-structure interaction with viscoelastic supports during waterhammer in a pipeline, Journal of Fluids and Structures, 54, April, pp. 215-234, 2015

26. Zielke W.: Frequency-dependent friction in transient pipe flow, Journal of Basic Engineering, ASME, 90, pp. 109-115, 1968.

\section{CONTACT WITH THE AUTHOR}

\author{
Kamil Urbanowicz \\ e-mail:kurbanowicz@zut.edu.pl \\ West Pomeranian University of Technology \\ Piastow 19, 70-310 Szczecin \\ Poland
}




\section{APPENDIX}

Coefficients describing effective weighting functions tested in the project are summarized in the following tables A1, A2, A3. These coefficients were scaled at the moment of turbulent flows occurrence using assumptions about their universality [17].

Tab. A1. Coefficients of effective two-component weighting functions

\begin{tabular}{|c|c|c|c|c|}
\hline L.p. & $\mathbf{m}_{1}$ & $\mathbf{m}_{2}$ & $n_{1}$ & $\mathbf{n}_{2}$ \\
\hline 2 terms - ver. I & 4.0951 & 28.6939 & 64.7685 & 2051.9391 \\
\hline 2 terms - ver. II & 6.6203 & 43.1553 & 119.9504 & 4542.6744 \\
\hline 2 terms - ver. III & 12.6592 & 77.0123 & 323.2014 & 14255.3890 \\
\hline 2 terms - ver. IV & 2.0902 & 16.3239 & 34.0614 & 713.6440 \\
\hline 2 terms - ver. V & 2.8889 & 21.5009 & 44.7999 & 1183.8544 \\
\hline
\end{tabular}

Tab. A2. Coefficients of effective three-component weighting functions

\begin{tabular}{|c|c|c|c|c|c|c|}
\hline L.p. & $\mathrm{m}_{1}$ & $\mathbf{m}_{2}$ & $\mathbf{m}_{3}$ & $\mathbf{n}_{1}$ & $\mathbf{n}_{2}$ & $\mathbf{n}_{3}$ \\
\hline 3 terms - ver. I & 2.6242 & 9.7852 & 34.972 & 48.007 & 559.25 & 6962.4 \\
\hline 3 terms - ver. II & 3.2982 & 11.849 & 42.078 & 61.214 & 796.30 & 10047.2 \\
\hline 3 terms - ver. III & 5.2734 & 17.691 & 62.299 & 110.32 & 1707.5 & 21933.6 \\
\hline 3 terms - ver. IV & 1.7214 & 6.7670 & 24.693 & 33.398 & 295.12 & 3509.8 \\
\hline 3 terms - ver. V & 2.1201 & 8.1537 & 29.394 & 39.376 & 404.41 & 4940.6 \\
\hline
\end{tabular}

Tab. A3. Coefficients of an effective ten-component weighting function

\begin{tabular}{|c|c|c|c|c|c|c|c|c|c|c|}
\hline L.p. & $\mathrm{m}_{1}$ & $\mathbf{m}_{2}$ & $\mathbf{m}_{3}$ & $\mathrm{~m}_{4}$ & $\mathbf{m}_{5}$ & $\mathrm{~m}_{6}$ & $\mathbf{m}_{7}$ & $\mathbf{m}_{8}$ & $\mathbf{m}_{9}$ & $\mathrm{~m}_{10}$ \\
\hline \multirow{3}{*}{10 terms } & 1 & 0.999651 & 1.0047 & 1.2446 & 2.328 & 4.43 & 8.0761 & 14.341 & 25.15 & 43.867 \\
\hline & $n_{1}$ & $\mathbf{n}_{2}$ & $\mathbf{n}_{3}$ & $\mathrm{n}_{4}$ & $\mathbf{n}_{5}$ & $n_{6}$ & $\mathbf{n}_{7}$ & $\mathbf{n}_{8}$ & $n_{9}$ & $\mathbf{n}_{10}$ \\
\hline & 26.3744 & 70.8493 & 135.072 & 226.194 & 417.598 & 946.783 & 2492.23 & 7100.19 & 20955.3 & 62745 \\
\hline
\end{tabular}

